\title{
Occurrence of granulocytic sarcoma after allogenic hematopoietic stem cell transplantation
}

\author{
Pamukcuoglu M1, Pepeler MS ${ }^{1}$, Ulkuden B ${ }^{1}$, Gocun PU ${ }^{2}$, Akyurek $N^{2}$, Akı SZ $^{1}$ and Sucak GT ${ }^{1}$ \\ ${ }^{1}$ Department of Hematology, Faculty of Medicine, Gazı University, Ankara, Turkey \\ ${ }^{2}$ Department of Pathology, Faculty of Medicine, Gaz1 University, Ankara, Turkey
}

\section{Introduction}

Myeloid sarcoma (MS), chloroma and granulositic sarcoma (GS) are all used to describe tumours which proliferate as a result of blasts in the extramedullary parts of the body [1]. Chloroma took its'name from the colour of the tumour [1,2]. It is usually green [1] Granulositic sarcoma occurs in Myelodysplastic syndrome (MDS), Chronic Myelocyter Leukemia (CML) and in 2-8\% of AML patients, at a younger age $[3,4]$. İt usually seen at 1-81 years of age and the size of GS can be from 2 to $20 \mathrm{~cm}$ [1]. Compression symptoms of pain and bleeding were as a result of the mass effect of GS. We determined the localizing of mass by Positron emission tomography with fluoroD-glucose integrated with computed tomography (FDG-PET CT) $[1,5]$. Mass is of containing immature granulocytic series cells and also pathological examination is very difficult [6]. There are three pathologic groups. Group-1 predominantly contains myeloblasts which are poorly differentiated. Group -2 contains moderately differentiated myeloblasts and promyelosites. Promyelosites are dominant. Group-3 contains an equal value of well matured promyelosites and myelosites [4]. Mitotic activity is very different in GS. KI-67/MIB1 score was always high (50\%$95 \%)[1,7]$. When we take a biopsy from a different part of the tumor mitotic activity can change [4]. Single body macrophage demonstrates faster tumor cell turnover [4], but GS does not always have uniform structure nor uniform chromosomal anomalies $[4,7]$.

GS occuring after Allogenic Stem Cell Transplantation (ASCT) has been an important issue in recent years [1]. Some parts of our body can escape from the stem cell protective effect against tumor cells. Treatment of GS which occurs after stem cell trasplantation (SCT) is very difficult for clinicians [4]. We need further studies to understand the occuring mechanism of GS to find a better choice of treatment.

\section{Materials and methods}

\section{Patients}

A total of 120 AML patients, who were treated with allogenic stem cell transplantation (ASCT), were enrolled in this study. We studied two diagnostic subgroups which included denova AML and secondary AML. Diagnosis of AML was made according to the World Health Organization (WHO) 2001 criteria and French-American-British (FAB) criteria. Risk stratification in AML was used to estimate sitogenetic findings, age, white blood cell count, minimal residual disease (MRD) and denova or secondary subtypes of AML. The risk assessment of patients was classified as low, intermediate and higher risk. We also used the European Bone Marrow Transplantation Risk Score (EBMT) and Hematopoetic Cell Transplantation-Comorbidity Index (HCT-CI/ SORROR) risk stratification in pre-transplant AML patients. According to the Eastern Cooperative Oncology Group (ECOG), patients were divided into two groups. In the first group (group-1) patients had ECOG-0 and ECOG-1; in the second group (group-2) patients had ECOG-2, ECOG-3 and ECOG-4. There were 108 patients in group-1 (90\%) and $12(10 \%)$ patients in group-2. We tried to determine the extramedullary disease (Granulocytic Sarcoma) at the relapse. We try to examine the factors that affect the extramedullary relapse (EMR) and anti-leukemic effect of graft-versus-host disease (GVHD).

\section{Statistical analyses}

SPSS 15 statistical program was used. Patients characteristics were calculated with descriptive statistics. We used chi-square test for categorical values while Mann Whitney $U$ test was used for noncategorical values. Cox-regression analysis was also used. $\mathrm{P}<0,05$ was considered to be of significant value.

\section{Results}

\section{General charateristics}

One hundred and twenty patients were included in this study. Seventhy (58.3\%) of the total 120 patients were male and $50(41.7 \%)$ were female. The median age of the patients was 38 years (min-max range: $18-64$ years). One hundred (83.3\%) patients had denova AML, $17(14,2 \%)$ had secondary AML.

Five $(4.2 \%)$ out of the total 120 patients were considered low risk, $25(20.8 \%)$ patients had intermediate risk and $87(72.5 \%)$ patients had higher risk. 3 (2,5\%) patients' risk was unknown at the time of diagnosis. Ninethy $(70 \%)$ of the patients were in remission following the first remission induction chemotherapy. Only 1 patient had allogenic stem cell transplantation (ASCT) under the progressive disease. According to the European Bone Marrow Transplantation (EBMT) Risk Score; 59 $(49,2 \%)$ patients had $>2$ risk level, $61(50,94 \%)$ patients had $\leq 2$ risk level prior to ASCT. According to the Sorror risk score; 106 (88.3\%) patients had $\leq 2$ risk score, $14(11,7 \%)$ patients had $>2$ risk score prior to ASCT.

One hundred and eight (90\%) patients had a full-match related donor, three $(2,5 \%)$ patients had a full-match relative donor, 7 (5.8\%) patients had a full-match unrelated donor, $2(1.7 \%)$ patients had non-

Correspondence to: Merve Pamukçuoğlu, MD, Department of Hematology, Ankara Numune Education and Research Hospital, Sihhiye 06500, Ankara, Turkey, Tel: 0090 (505) 2458374; E-mail: drmpamuk@yahoo.com

Received: January 04, 2018; Accepted: January 23, 2018; Published: January 26, 2018 
full-match sibling donors. 111 (92,5\%) patients had 10/10 HLA match donors, $6(5 \%)$ patients had a 9/10 HLA match donor, 3 (2.5\%) patients had a $8 / 10$ HLA match donor.

Peripheral stem cell was used in $118(98,3 \%)$ patients and bone marrow stem cell was used in only $2(1,7 \%)$ patients. The median count of CD34+ cells was $4 \times 10^{6}$ (min-max: $\left.1.26 \times 10^{6}-8.20 \times 10^{6}\right)$.

One hundred and four $(86,7 \%)$ patients had myeloablative region, $16(13,3 \%)$ patients had non-myeloablative region prior to ASCT and only 4 patients had total body irradation (TBI).

Following the ASCT 77 (64,2\%) patients had Greft Versus Host Disease (GVHD) while $43(35,8 \%)$ patients had no GVHD. Out of 77 patients 17 patients had acute GVHD, 47 patients had chronic GVHD and 7 patients had both acute and chronic GVHD, 1 patient had hyperacute GVHD, 7 patients had acute and chronic GVHD, 3 patients had hyperacute and acute GVHD, 2 patientshad acute, hyperacute and chronic GVHD. For the prophylactic treatment of GVHD; methtraxate and cyclosporin were administered to $112(93,3 \%)$ patients, the other 8 $(6,7 \%)$ patients receiving cyclosporin and micofenalat mofelit (MMF) (Table 1 show the general characteristics of patients),

\section{Extramedullary relaps}

Post-transplant relapse was seen in 39 (33.3\%) patients; 31 (25.8\%) of these 39 patients had bone marrow relapse, $6(5 \%)$ had extramedullary relapse and $2(1,7 \%)$ had both extramedullary and bone marrow relapse. Eightysix $(71,7 \%)$ out of 120 patients had immunosuppressive treatment and $16(\% 13,3)$ patients had lost their chimerism at the time of relapse. Of the 6 extramedullary relapse patients two had periorbital soft tissue relapse, 1 had breast soft tissue relapse, 2 had paragingival soft tissue relapse, 1 had lumbosacral and sternal soft tissue relapse, 1 had submandibular relapse.

The median age of this 8 patients were 26 years-old (minmax:20-44). One of the 8 patients risk had low risk, 6 of them had high and one of them had unknown at the initial. Three of the 8 patients were AML M1, 2 of the 8 patients was AML-M0, 3 of the 8 patients were AML-M2.

EMR relaps duration after the ASCT was median 685 days (minmax:30-6935 days). Leukemia relaps duration of 31 patients after ASCT was median 1070 days (min-max: 29-1400 days). Four of the eight patients had immunesupresive treatment when EMR was occured. All of the EMR patients treated with a myeloablative treatment. 5 of the 8 patients treated with a peroral busulfan treatment, 2 of them treated with intravenouse busulfan treatment and 1 of them was not treated with busulfan.

Donor lymphocyte infusion (DLI) treatment was given to 22 $(18,3 \%)$ patients after relaps. All of the eight patients had donor lymphosit infusion (DLI) treatment after the relaps and also discontinue of the immunesupresive treatment. Six (\%75) patients treated with 1 bagage of DLI, 2 (\% 25) patients treated with 2 bagage of DLI. Five $(\% 62,5)$ patients had remission, $3(\% 37,5)$ patients had not remisssion after the DLI treatment. Four (\%50) of the 8 patients had GVHD after the DLI treatment. Six (\%75) of the 8 patients had complete remission, the other 2 patients treated with chemoterapy again, none of the patients had second stem cell transplantation (Table 2 show the general characteristics of EMR patients).

The gender, AML subtype (denova or secondary), risk of disesea at the time of diagnosis, ECOG, the number of induction chemotherapy treatments, $\mathrm{CD}^{+} 4^{+}$infusion cell counts, TBI treatment, the EBMT and Sorror risk scores and GVHD did not affect extramedullary relapse $(p>0.05)$. However loss of chimerisms did have an effect on extramedullary relapse $(\mathrm{p}<0.05)$.

\section{Discussion}

Donor lymphocyte infusion (DLI) after SCT has a protective effect on bone marrow relapse but unfortunately has a less protective effect on EMR $[8,9]$. T cells may not reach EM sites and the immunological and repaired effect of $\mathrm{T}$ cells does not occur [8]. There is a lot of immunological escape mechanism in the extramedullary site of the body; for example there is down regulation of the FAS antigen and induction of FAS ligand expression [8]. Some parts of our body can escape the anti-leukemic effect of DLI or stem cell [8]. In addition, EMR may be caused as a result of the SCT partial loss of chromosome $6 p$ [10]. One way in which EMR occurs is the traffic of T cells and NK cells. NK cells and T cells were higher in BM than in extramedullary tissue. Inflammations of extramedullary tissue and CD56 antigens had an important effect on the relapse. The GVL effect occurs in BM. This caused an inflammation of BM and changed the traffic of T cells. This protected BM rather than EM tissue. CD56 antigens were seen on NK cells. Some of the tissue had far more NK cells than other parts, such as neural tissuea, gut, pancreas, thyroid gland, adrenal gland, testes, ovary, visceral smooth muscle and cardiac muscle. As a result of these CD56 cells, tumour cells were homing this tissue and EMR occurred [5].

İsolated GS was very rarely seen [11]. The skin, lymph node, dura, soft palate, nasopharynx, orbit, testes, brain, salivary gland, anterior mediastinum, vagina, breast and skin, gynecological tract, pleura, chest wall, retroperitoneum and small intestine, pancreas were the areas of the body where it was seen to occur $[4,6,12-15]$. Granulositic sarcoma sometimes occurred only in a diffuse infiltration of skin without mass and bone marrow leukemia [2]. The most common sites of the body where this occurred were the periosteum, soft tissue, bone, lymph node and skin [6].

In recent years, extramedullary relapse (EMR) has been a very common topic of discussion after transplantation [1]. ASCT has been used in both acute lymphobastic lymphoma (ALL) and AML treatment [8]. We know that the anti-leukemic effect of GVHD protects patients from disease relapse especially as far as bone marrow is concerned [8]. The anti-leukemic effect of GVHD on the extramedullary site was less $[1,8]$. As in literature, we did not find any significant relationship between GVHD and non-GVHD patients with EMR.

After the ASCT, the duration of the relapse was longer in EMR than in cases of bone marrow relapse, especially 4-50 months after transplantation $[1,5]$ and also EMR were more frequently seen after ASCT than following chemotherapy treatment and authologeous stem cell transplantation $[5,8,9]$. In this study we had 8 patients in whom GS came about after SCT and the relapse duration ranges of these patients varied from 1 to 24 months.

EMR was seen more commonly if a patient had AML M4-M5, advanced disease (higher risk) or had unfavorable cytogenetics [5]. In our study, those patients who relapsed with EMR after SCT were all of a younger age (20-44 years old). 3 of them had higher risk at the time of diagnosis just as in other literature. In contrast, extra medullary relapsed patients were usually diagnosed AML-1 and AML-2.

Only one EMR patient was treated with total body irrigation (TBI) pretransplant regimen. In our study, the remaining patients were treated with busulfan pretransplant regimen in contrast to other literature. We know that EMR was seen less in busulfan based condition than in TBI 
[5]. Especially acute or chronic GVHD has been observed with EMR patients just as in our own study [8].

GS has no standard treatment and usually worsens as a result of treatment $[1,4,7,11,16,17]$. Early diagnosis and treatment of the disease is very important [3]. The best means of treatment is still chemo-radiotherapy [18]. We treated all GS with cytarabine based chemotherapy in the same way as AML $[5,12]$ and local radiotherapy [1]. Stem cell transplantation was a standard treatment for isolated granulocytic sarcoma patients but there was no such kind of therapy for relapsed GS after stem cell transplantation [19,20].

Relapsed GS after SCT can depend on the host or donor source [13]. This can be understood from the chimerism of patients. If there was no loss of chimerism, it was shown that GS came from the donor stem cell [13]. However if there was loss of chimerism, it was shown that GS came from host source. There were also variable escape mechanism of the anti-leukemic effect of the stem cell. The main result taken from this limited number of patients is loss of chimerism have affect on occuring GS (host or donor source GS) after stem cell transplantation. We need to save patient's chimerism after stem cell transplantation protecting from EMR. There are a lot of factors and immunological mechanisms which may affect the occurrence of GS after SCT. If we can determine these factors and immunological mechanisms then we will be able to easily prevent the occurrence of GS by providing effective treatment against such mechanisms.

\section{References}

1. Avni B, Koren-Michowitz M (2011) Myeloid sarcoma: current approach and therapeutic options. Ther Adv Hematol 2: 309-16. [Crossref]

2. Aboutalebi A, Korman JB, Sohani AR, Hasserjian RP, Louissaint A Jr, et al. (2013) Aleukemic cutaneous myeloid sarcoma. J Cutan Pathol 40: 996-1005. [Crossref]

3. Yamauchi K, Yasuda M (2002) Comparison in treatments of nonleukemic granulocytic sarcoma: report of two cases and a review of 72 cases in the literature. Cancer 94: 1739-46. [Crossref]

4. Meis JM, Butler JJ, Osborne BM, Manning JT (1986) Granulocytic sarcoma in nonleukemic patients. Cancer 58:2697-709. [Crossref]

5. Yoshihara S, Ando T, Ogawa H (2012) Extramedullary relapse of acute myeloid leukemia after allogeneichematopoietic stem cell transplantation: an easily overlooked but significant pattern of relapse. Biol Blood Marrow Transplant 18: 1800-7. [Crossref]

6. Neiman RS, Barcos M, Berard C, Bonner H, Mann R, et al. (1981) Granulocytic sarcoma: a clinicopathologic study of 61 biopsied cases. Cancer 48: 1426-37. [Crossref]
7. Pileri SA, Ascani S, Cox MC, Campidelli C, Bacci F, et al. (2007) Myeloid sarcoma: clinico-pathologic, phenotypic and cytogenetic analysis of 92 adult patients. Leukemia 21: 340-50. [Crossref]

8. Lee JH, Choi SJ, Lee JH, Seol M, Lee YS, et al. (2005) Anti-leukemic effect of graftversus host disease on bone marrow andextramedullary relapses in acute leukemia. Haematologica 90: 1380-8. [Crossref]

9. Curley C, Durrant S, Kennedy GA (2013) Is extramedullary relapse of acute myeloid leukemia after allogeneic hematopoietic stem cell transplantation associated with improved survival? Asia Pac J Clin Oncol 9: 285-9. [Crossref]

10. Spitzer TR (2012) Changing stripes to avoid graft versus leukemia. Transplantation 93: 674-675. [Crossref]

11. Lou Y, Qian W, Meng H, Tong Y, Jin J (2012) Frequent extramedullary recurrence of isolated myeloid sarcoma in the long-term follow-up. Ann Hematol 91: 1317-9. [Crossref]

12. Tsimberidou AM, Kantarjian HM, Wen S, Keating MJ, O'Brien S, et al. (2008) Myeloid sarcoma is associated with superior event-free survival and overall survival compared with acute myeloid leukemia. Cancer 113: 1370-8. [Crossref]

13. Tabriz N, Tannapfel A, Griesinger F, Weyhe D (2013) Chloroma of pancreas-initial manifestation of a secondary leukemia after stem cell transplantation case report and review of the literature. J Gastrointest Surg 17: 1331-5. [Crossref]

14. Toumeh A, Phinney R, Kobalka P, Mohamed I (2012) Bilateral myeloid sarcoma of the breast and cerebrospinal fluid as a relapse ofacute myeloid leukemia after stem-cell transplantation: a case report. J Clin Oncol 30: 199-01. [Crossref]

15. ChoSF, LiuTC, ChangCS (2013) Isolated central nervous system relapse presenting a myeloid sarcoma ofacute myeloid leukemia after allogeneic peripheral blood stem cell transplantation. Ann Hematol 92: 133-5.

16. Shimizu H, Saitoh T, Tanaka M, Mori T, Sakura T, et al. (2012) Allogeneic hematopoietic stem cell transplantation for adult AML patients with granulocytic sarcoma. Leukemia 26: 2469-73. [Crossref]

17. Breccia M, Mandelli F, Petti MC, D'Andrea M, Pescarmona E, et al. (2004) Clinicopathological characteristics of myeloid sarcoma at diagnosis andduring followup: report of 12 cases from a single institution. Leuk Res 28: 1165-9. [Crossref]

18. Ghadiany M, Attarian H, Hajifathali A, Khosravi A, Molanaee S (2008) Relapse of acute myeloid leukemia as isolated bilateral testicular granulocyticsarcoma in an adult. Urol J 5: 132-5. [Crossref]

19. Antic D, Elezovic I, Milic N, Suvajdzic N, Vidovic A, et al. (2013) Is there a "gold" standard treatment for patients with isolated myeloid sarcoma? Biomed Pharmacother 67: 72-7. [Crossref]

20. Sanna M, Caocci G, Vacca A, Piras E, Orrù F, et al. (2013) Daunorubicin, cytarabine, and cladribine regimen plus radiotherapy and donorlymphocyte infusion for extramedullary relapse of acute myeloid leukemia after hematopoietic stem cell transplantation. Case Rep Hematol 2013: 258028. [Crossref]

Copyright: (C2018 Pamukcuoglu M. This is an open-access article distributed under the terms of the Creative Commons Attribution License, which permits unrestricted use, distribution, and reproduction in any medium, provided the original author and source are credited. 